\title{
The Influence of Social-Cognitive Factors on Personal Hygiene Practices to Protect Against Influenzas: Using Modelling to Compare Avian A/H5N1 and 2009 Pandemic A/H1N1 Influenzas in Hong Kong
}

\author{
Qiuyan Liao • Benjamin J. Cowling • \\ Wendy Wing Tak Lam • Richard Fielding \\ Published online: 15 October 2010 \\ (C) The Author(s) 2010. This article is published with open access at Springerlink.com
}

\begin{abstract}
Background Understanding population responses to influenza helps optimize public health interventions. Relevant theoretical frameworks remain nascent.

Purpose To model associations between trust in information, perceived hygiene effectiveness, knowledge about the causes of influenza, perceived susceptibility and worry, and personal hygiene practices (PHPs) associated with influenza.

Methods Cross-sectional household telephone surveys on avian influenza A/H5N1 (2006) and pandemic influenza A/ H1N1 (2009) gathered comparable data on trust in formal and informal sources of influenza information, influenzarelated knowledge, perceived hygiene effectiveness, worry, perceived susceptibility, and PHPs. Exploratory factor analysis confirmed domain content while confirmatory factor analysis was used to evaluate the extracted factors. The hypothesized model, compiled from different theoretical frameworks, was optimized with structural equation modelling using the A/H5N1 data. The optimized model was then tested against the $\mathrm{A} / \mathrm{H} 1 \mathrm{~N} 1$ dataset.

Results The model was robust across datasets though corresponding path weights differed. Trust in formal information was positively associated with perceived hygiene
\end{abstract}

Q. Liao $\cdot$ W. W. T. Lam $\cdot$ R. Fielding $(\bowtie)$

Health Behavior Research Group,

Department of Community Medicine, School of Public Health,

The University of Hong Kong,

21 Sassoon Road,

Pokfulam, Hong Kong, China

e-mail: fielding@hku.hk

B. J. Cowling

Infectious Diseases Group, Department of Community Medicine,

School of Public Health, The University of Hong Kong,

21 Sassoon Road,

Pokfulam, Hong Kong, China effectiveness which was positively associated with PHPs in both datasets. Trust in formal information was positively associated with influenza worry in $\mathrm{A} / \mathrm{H} 5 \mathrm{~N} 1$ data, and with knowledge of influenza cause in $\mathrm{A} / \mathrm{H} 1 \mathrm{~N} 1$ data, both variables being positively associated with PHPs. Trust in informal information was positively associated with influenza worry in both datasets. Independent of information trust, perceived influenza susceptibility associated with influenza worry. Worry associated with PHPs in A/H5N1 data only. Conclusions Knowledge of influenza cause and perceived PHP effectiveness were associated with PHPs. Improving trust in formal information should increase PHPs. Worry was significantly associated with PHPs in A/H5N1.

Keywords Social-cognitive · Personal hygiene practices . Influenza $\cdot$ Chinese $\cdot$ Trust in information

\section{Introduction}

Novel respiratory infectious diseases (RIDs) such as severe acute respiratory syndrome (SARS), avian influenza A/ H5N1 and most recently pandemic influenza A/H1N1 represent serious public health threats. For influenzas, antivirals enable treatment of infected individuals and chemoprophylaxis of exposed individuals throughout the first wave until vaccines are developed. Non-pharmaceutical interventions may also delay local transmission and mitigate the impact of local epidemics [1]. Although $\mathrm{A} / \mathrm{H} 5 \mathrm{~N} 1$ is predominantly a disease of domestic fowl $[2,3]$ and rarely occurs among humans, its very high mortality rate and high potential for mutation to readily transmit between humans remain of great concern. In contrast, $\mathrm{A} / \mathrm{H} 1 \mathrm{~N} 1$ is highly contagious among humans but has in most cases a relatively benign clinical profile and low mortality rate [4]. 
Personal hygiene practices (PHPs) including respiratory etiquette (covering mouth when sneezing or coughing, appropriate disposal of tissues), hand cleansing with soap/ alcohol/biocides ("hand-washing") and other hygiene practices, such as using serving utensils are widely recommended for reducing influenza virus transmission as simple, inexpensive and effective interventions [1, 5-7]. Hand-washing in particular reduces influenza viral load on hands, thereby reducing chances of self-inoculation and onward transmission via fomites [5]. Understanding the determinants of PHPs in RIDs is an important public health question.

Hand-washing, wearing face masks and social distancing (health protective behaviours) increase during epidemics [8, 9], and adherence varies with perceived health threats and efficacy beliefs and demographics [10-15]. Most relevant studies are cross-sectional and of the 26 studies recently reviewed 23 lacked robust theoretical frameworks [10, 11]. Several theoretical models for understanding health protective behaviours are available, including the cognitively based Theories of Planned Behaviour (TPB) $[16,17] /$ Reasoned Action (TRA) [18, 19], Health Belief Model (HBM) [20, 21] and Protection Motivation Theory [22]. Although HBM and TPB among others have been applied in some studies of cognitive interactions with health protective behaviours during RIDs [15, 23, 24], these models do not adequately accommodate affect in health behavioural change during RID epidemics/pandemics. Moreover, existing theories have poorly accommodated the spectrum of social influence, exceptions being the TPB/ TRA, which include coercive influences from family and friends under "norms", and Social Learning Theory (SLT) [25], which describes observational learning. Neither theoretical position includes both. Some studies have explored combinations of different theories. For example, attempts to predict hand-washing on an intensive care unit by combining SLT and TPB elements found only self-efficacy predicted hand-washing [26], suggesting established theoretical models may be inadequate. Because outbreaks of RIDs are dynamic, embodying significant uncertainty and often, invisible personal threat they differ from non-communicable disease. That the source of threat is not one's own behaviour but other people argues for social factors to be more influential than existing models of behaviour change allow.

The very limited literature on behavioural adherence to prevention during infectious respiratory epidemics suggests perceived effectiveness of recommended action and perceived risk consistently associate with health protective actions [10-15]. To enable individual determination of risk, information on threat characteristics relative to self is needed. Trust is a core element in risk perception [12] and influences perceived veracity of information from different sources. During epidemics, trust in information becomes important when people consider making informed decisions to change behaviour [27]. The public is usually passively exposed to epidemic-related information from government agencies via the media but more active searching may occur if perceived threat levels are high and imminent [28]. Trust in information is associated with health protective behaviour adherence during epidemics [11, 13-15, 23], but observing the actions of others also provides information $[25,29]$. In particular, during conditions of high uncertainty, for example during the early stages of an epidemic, people may seek information from a much broader array of sources, including observations of the actions of peers and affiliates (social learning) and from cautionary tales (cultural learning) if government/media information is lacking, inadequate, incomplete or unreliable [8, 30]. Existing theoretical models poorly integrate such broader social influences with affective and cognitive elements.

Communication theories [31, 32] and other studies [33] suggest that risk communications influence cognitive processes to produce protective behaviours. Awareness of RID epidemic (and other) situations arise from perceptions, comprehension and prediction of the prevailing (threat) environment [34, 35], being informed by both formal information (government/media news) and informal information (conversations or observation of the behaviour of friends, colleagues and others) sources. Such situation awareness subsumes several cognitive elements: Information is sought on the nature of the threat and protective actions because threat-related primary and secondary appraisal requires cognizance of threat characteristics and response options (causal knowledge, perceived susceptibility and utility of and effectiveness of protective response options) [34] and control of negative affect, which influences judgments of threat and action effectiveness [34-37]. These elements of situational awareness offer potentially useful insights for predicting lay protective health behaviours during emerging RID epidemics [33, 38]. We developed and tested a theoretical model (Fig. 1) derived from the above literature incorporating three domains: trust in both formal and informal information sources, situation awareness (causal knowledge; perceived effectiveness of PHP (effectiveness); perceived susceptibility to and worry about influenza) and reported recent PHPs (Fig. 1). The model proposes that information trust influences situation awareness variables, which in turn influence PHPs. We used structural equation modelling to test a saturated (all paths between all variables are assumed) model as the null hypothesis. We hypothesized that greater trust in formal information would reflect elements of situational awareness embodying greater knowledge of disease, greater perceived PHP effectiveness, lower perceived susceptibility and less worry. This would be associated with enhanced PHP. In contrast, trust in informal information would reflect elements of situational awareness 
Fig. 1 The conceptual framework: interactions among social information trust, situational awareness and health protective behaviours

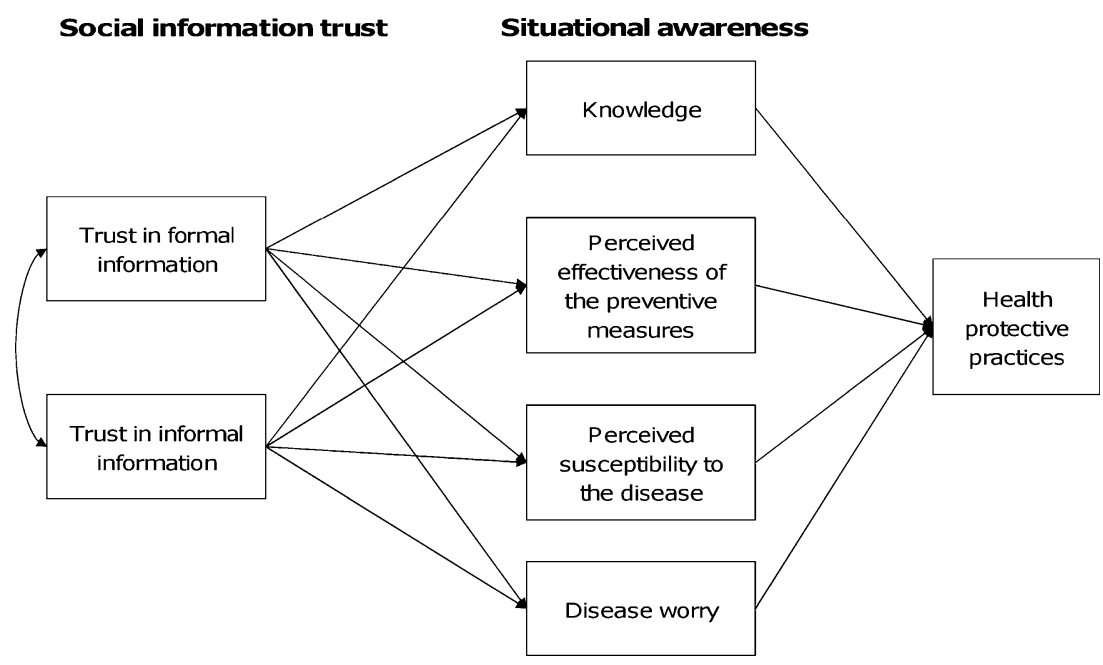

embodying less knowledge of disease, lower perceived PHP effectiveness, greater perceived susceptibility and worry, and uncertain PHP.

This study utilized data collected in 2006 during high levels of A/H5N1 activity in southern China [39] and during the $2009 \mathrm{~A} / \mathrm{H} 1 \mathrm{~N} 1$ pandemic [40] to test the hypothesized model. Comparing the model in these two different epidemic situations helps to validate the model's robustness under different, but not unrelated circumstances.

\section{Methods}

\section{Sources of Data}

Both data sets were gathered using anonymous random household telephone interviewing with one adult within each household selected using randomization tables based on household size, in the general Hong Kong population $[39,40]$. Data on risk perception, knowledge, attitudes and hygiene practices towards $\mathrm{A} / \mathrm{H} 5 \mathrm{~N} 1$ influenza were collected between December 2005 to March 2006 when A/H5N1 influenza reached its epidemic peak in South East Asia. Similar data were collected for A/H1N1 influenza using comparable methods on 13-15th May 2009, shortly after the WHO global alert on 24th April 2009 and the identification of the first laboratory-confirmed imported case in Hong Kong on 1st May 2009 [41]. Both surveys obtained ethics approval from the Institutional Review Board of the University of Hong Kong/Hospital Authority Hong Kong West Cluster and verbal consent was required from all respondents.

\section{Measures}

Both surveys assessed variables relevant to this study, including hygiene practices, trust in formal and informal information, risk and related perceptions (Cronbach's alphas and related scale information can be found in Appendix Table 1). We selected items related to the three domains specified in Fig. 1.

\section{Trust in Formal and Informal Information}

Seven items addressed trust in information. Four items were designed to tap trust in formal and three items to tap trust in informal information in the $\mathrm{A} / \mathrm{H} 5 \mathrm{~N} 1$ survey, while in the $\mathrm{A} /$ H1N1 survey six items addressed trust; four tapped trust in formal and two in informal information. The items were treated as a scale and asked the respondents about their agreement (5-point scale) with statements such as, "Media reports about (A/H5N1/A/H1N1) can be trusted." Although domain items differed slightly by survey, exploratory factor analysis with varimax rotation generated two factors comprising Trust in formal information (government or media news) and Trust in informal information (conversations or behaviours of friends, colleagues and others) for both surveys (Appendix Table 1). All factor loadings exceeded 0.60. Confirmatory factor analysis (CFA) was then conducted to evaluate the adequacy of the measurement models, indicating good fit for the measurement models in both surveys with confirmatory fit index (CFI) $>0.97$ and root mean squared error of approximation (RMSEA) $<0.05$.

Awareness of Epidemic Situation

Disease-related Knowledge and Worry Five items addressed diseases-related knowledge and worry, which again differed slightly by survey. Two factors were extracted with varimax-rotated exploratory factor analysis comprising self-reported knowledge and disease worry (Appendix Table 1). All factor loadings exceeded 0.65. Confirmatory factor analysis indicated a good fit with CFI $>0.99$ and RMSEA $<0.05$. 
Perceived Susceptibility In both surveys, perceived susceptibility was assessed with single items asking respondents to estimate the likelihood of contracting $\mathrm{A} / \mathrm{H} 5 \mathrm{~N} 1$ or $\mathrm{A} /$ H1N1 (7-point Likert scale) (Appendix Table 1).

Perceived Hygiene Effectiveness Perceived effectiveness of hygiene measures for preventing $\mathrm{A} / \mathrm{H} 5 \mathrm{~N} 1 / \mathrm{A} / \mathrm{H} 1 \mathrm{~N} 1$ was assessed with two items asking respondents about their beliefs in the effectiveness (completely ineffective/somewhat ineffective/unsure/somewhat effective/highly effective) of washing hands before touching face or food and of washing hands after going out (Appendix Table 1). In both surveys, all factor loadings exceeded 0.87 .

\section{Health Protective Behaviours}

Because provisional data analysis suggested that personal hygiene, social distancing, face-mask use and other protective practices have heterogeneous determinants [14, 40, 42], we used personal hygiene (respiratory etiquette, hand washing and serving utensil use) as PHP only. Three of four items in the A/H5N1 survey were common to the A/ H1N1 survey (Appendix Table 1). Four and three items comprised assessment of personal hygiene practices for $\mathrm{A} /$ $\mathrm{H} 5 \mathrm{~N} 1$ and $\mathrm{A} / \mathrm{H} 1 \mathrm{~N} 1$, respectively. Each item was scored on a 4-point categorical scale ("Always", "Usually" "Sometimes" and "Never"). Scores for all three items were combined and the total score was used as a latent variable of PHP for the purposes of structural equation modelling. Using CFA factor loadings ranged between 0.55 and 0.75 for $\mathrm{A} / \mathrm{H} 5 \mathrm{~N} 1$ items and $0.62-0.74$ for $\mathrm{A} / \mathrm{H} 1 \mathrm{~N} 1$ items.

\section{Statistical Analysis}

Excepting perceived susceptibility, measured on a single ordinal item, other constructs were specified as latent variables and measured with two or more items. Sample characteristics for the two surveys were compared with the general population using Cohen's effect sizes [43]. Relevant data from each survey operationalizing domains specified in the conceptual model (Fig. 1) were entered into the Structural Equation Model (SEM). Multivariate outliers were identified and deleted based on relative contribution to normalized multivariate kurtosis (nonnormality). SEM requires continuous data with multivariate normal distribution. This was estimated using Mardia's coefficient [44]. Missing data were handled with multiple imputation [45] to generate ten datasets which were summarized into one for subsequent analysis, to maintain sample size and maximize available data [46]. Standardized parameters $(\beta)$ were estimated based on the summarized datasets. Standardized parameters $>0.10$ accompanied by $p$ values $\leq 0.05$ were considered as meaningful; Standardized parameters $<0.10$ but accompanied by $p$ values $\leq 0.05$ were considered weak and not meaningful. Those with associated $p$ values $\geq 0.05$ were non-significant. Misfitting or poorly fitting models were re-specified guided by theoretical soundness and the Lagrange Multiplier test (LMtest) which tests if the addition of (specified) parameters (paths) improves model fit and the Wald Test (Wtest) which identifies parameters that can be removed without reducing the model fit [47].

To evaluate model fit, multiple fit indices were examined; as each has some shortcomings when used alone we used a combination for robustness. Because $\chi^{2}$ goodness of fit is sensitive to sample size, we required a $\chi^{2} / d f$ value of $<3$ as favourable for large sample sizes such as those in the present study and used the Satorra-Bentler (SB) $\chi^{2}$ which incorporates an adjustment for non-normal distributions [48]. Values of non-normalized fit index (NNFI) range from 0 to 1.0 with values $>0.90$ indicating a good fit. Comparative Fit indices (CFI) produce the same value ranges as NNFI, where values exceeding 0.90 and 0.95 indicate acceptable and good fit respectively. Finally, RMSEA indicates model misfitting, where values exceeding 0.05 indicate an inadequate model fit. All fit indices were calculated and used to evaluate model fit [49]. All statistical analyses were conducted in EQS 6.1 for Windows [50].

\section{Results}

The $\mathrm{A} / \mathrm{H} 5 \mathrm{~N} 1$ survey comprised 1,760 respondents with a response rate of $63 \%$ while the $\mathrm{A} / \mathrm{H} 1 \mathrm{~N} 1$ survey comprised 1,016 respondents with a response rate of $68.8 \%$. Demographics including age, gender, education level, marital status and birth place of the two samples were comparable to the general population [51] (effect sizes $<0.3$ ) [43] but differed somewhat from each other (Appendix Table 2), with the $\mathrm{A} / \mathrm{H} 1 \mathrm{~N} 1$ sample more closely approximating the general population in terms of gender and age, and the $\mathrm{A} / \mathrm{H} 5 \mathrm{~N} 1$ sample closer in terms of educational attainment and marital status.

There were some demographic differences in the constructs specified in the model (Appendix Table 3). PHPs were generally greater in females across the two surveys but were unassociated with age. Perceived effectiveness of hygiene and disease worry were higher in females in the A/ H5N1 survey only but positively associated with age in both surveys. Perceived susceptibility was negative associated with age in the $\mathrm{A} / \mathrm{H} 5 \mathrm{~N} 1$ data but positively associated with age in the $\mathrm{A} / \mathrm{H} 1 \mathrm{~N} 1$ data. Trust in formal information was higher in females and positively associated with age in the $\mathrm{A} / \mathrm{H} 5 \mathrm{~N} 1$ data only while trust in informal information was positively associated with age but did not differ by gender in either dataset. 
In the $\mathrm{A} / \mathrm{H} 5 \mathrm{~N} 1$ data, three cases were identified and deleted as outliers based on disproportionate contribution to normalized multivariate kurtosis, leaving 1,757 cases for model testing. Similarly, four cases were identified and deleted as outliers in the A/H1N1 data, leaving 1,012 cases for model testing. Mardia coefficients (63.68 and 41.68 for $\mathrm{A} / \mathrm{H} 5 \mathrm{~N} 1$ and $\mathrm{A} / \mathrm{H} 1 \mathrm{~N} 1$ survey data, respectively) indicated some degree of persisting non-normality for both survey datasets, thus robust maximum likelihood estimation and $\mathrm{SB} \chi^{2}$ were applied for model testing.

The Full Structural Model

We are proposing that the situational awareness variables in the model (centre column, Fig. 1) are intervening variables between information trust and hygiene behaviours. Our null hypothesis specified a model wherein all paths between social information trust and situational awareness, and between situational awareness and PHPs were assumed to be significant (Fig. 1). This null model, tested first against $\mathrm{A} / \mathrm{H} 5 \mathrm{~N} 1$ and then $\mathrm{A} / \mathrm{H} 1 \mathrm{~N} 1$ data, proved an unsatisfactorily poor fit. We next re-specified the hypothesized model on the A/H5N1 data and then applied this re-specified model to the $\mathrm{A} / \mathrm{H} 1 \mathrm{~N} 1$ data, which required further optimization. The optimized models are shown in Fig. 2 for the A/H5N1 data and Fig. 3 for the A/H1N1 data (Fig. 3).

\section{$\mathrm{A} / \mathrm{H} 5 \mathrm{~N} 1$}

The hypothesized SEM algorithm was initially run using LMtests to assess missing paths. Two significant LMtest values suggested that including two additional parameters, a path-linking self-reported knowledge to perceived hygiene effectiveness and a path linking perceived susceptibility to disease worry, would significantly improve model fit. These two paths were theoretically plausible. The first path being consistent with Bandura's view that knowledge guides judgments and action $[25,29]$. The latter path being consistent with previous findings that worry mediates the relationship between perceived susceptibility and health protective behaviours $[52,53]$. Both paths enhance the interaction of situational awareness variables in the model. Both paths were added and the SEM reiterated using Wtests to optimally parse the model by removing any unnecessary paths. Non-significant Wtests indicated that three parameters contributed little explanatory power and could be removed for parsimony: paths linking trust in informal information to self-reported causal knowledge, trust in informal information to perceived hygiene effectiveness, and trust in informal information to perceived susceptibility were deleted. The final A/H5N1 SEM is shown in Fig. 2. Solid lines with standardized parameters $(\beta)$ indicate significant paths with $\beta \mathrm{s}>0.1$; statistically significant paths with $\beta \mathrm{s}<0.1$ were retained and are shown with dotted lines; non-significant paths are removed from the model. Fit indices implied a good model fit with $\mathrm{SB} \chi^{2} / d f=1.48, \mathrm{NNFI}=0.98, \mathrm{CFI}=0.95$ and RMSEA $=0.02$.

The optimized model showed that greater trust in formal information was positively associated with perceptions of greater hygiene effectiveness $(\beta=0.25)$ and more influenza worry ( $\beta=0.24)$ (Fig. 2). Greater trust in informal information was associated only with greater influenza worry $(\beta=$ $0.31)$. Self-reported knowledge $(\beta=0.24)$, perceived hygiene effectiveness $(\beta=0.23)$ and disease worry $(\beta=0.28)$ were positively associated with personal hygiene practices. Better self-reported knowledge was associated with greater perceived hygiene effectiveness $(\beta=0.15)$ while greater perceived susceptibility was associated with more influenza worry ( $\beta=0.18$ ). Other retained (dashed, Fig. 2) paths were statistically significant but all had $\beta<0.1$ indicating their respective variables were only weakly associated. The model explained $21.8 \%$ of the variance in PHPs against A/H5N1.
Fig. 2 Structural equation model for personal hygiene practices against avian influenza $\mathrm{A} / \mathrm{H} 5 \mathrm{~N} 1$, 2006, Hong Kong; all numbers represent standardized parameters $(\beta)$; solid lines are statistically significant and have $\beta \mathrm{s}>0.10$; dotted lines are statistically significant but have $\beta \mathrm{s}<0.10$

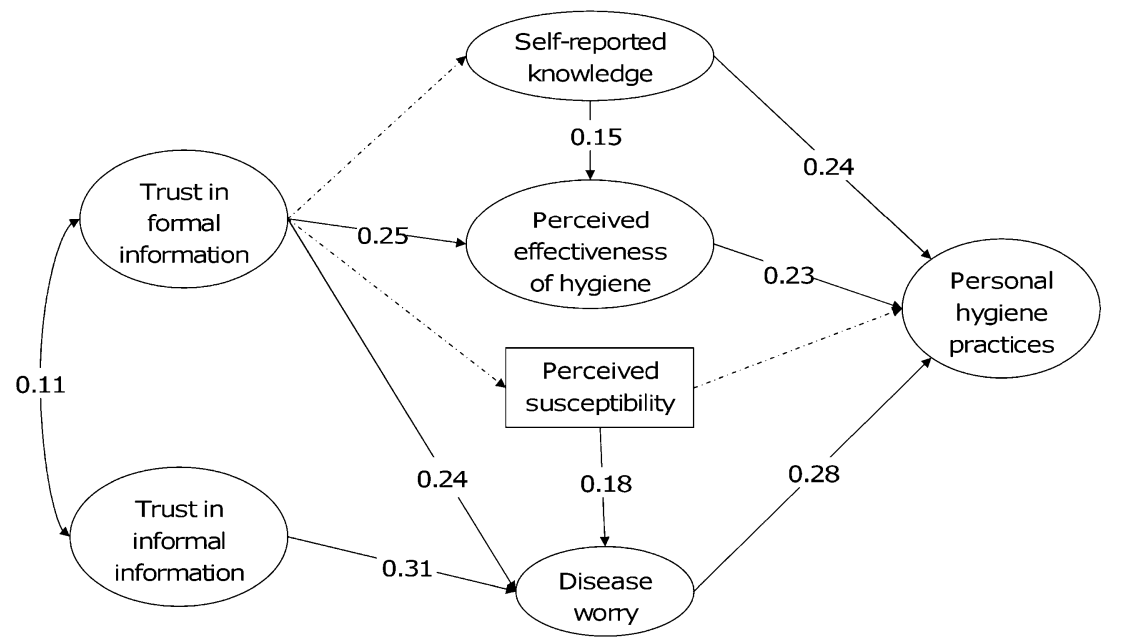


Fig. 3 Structural equation model for personal hygiene practices against novel influenza $\mathrm{A}$ / H1N1, 2009, Hong Kong; all numbers represent standardized parameters $(\beta)$; solid lines are statistically significant and have $\beta \mathrm{s}>0.10$; dotted lines are statistically significant but have $\beta \mathrm{s}<0.10$

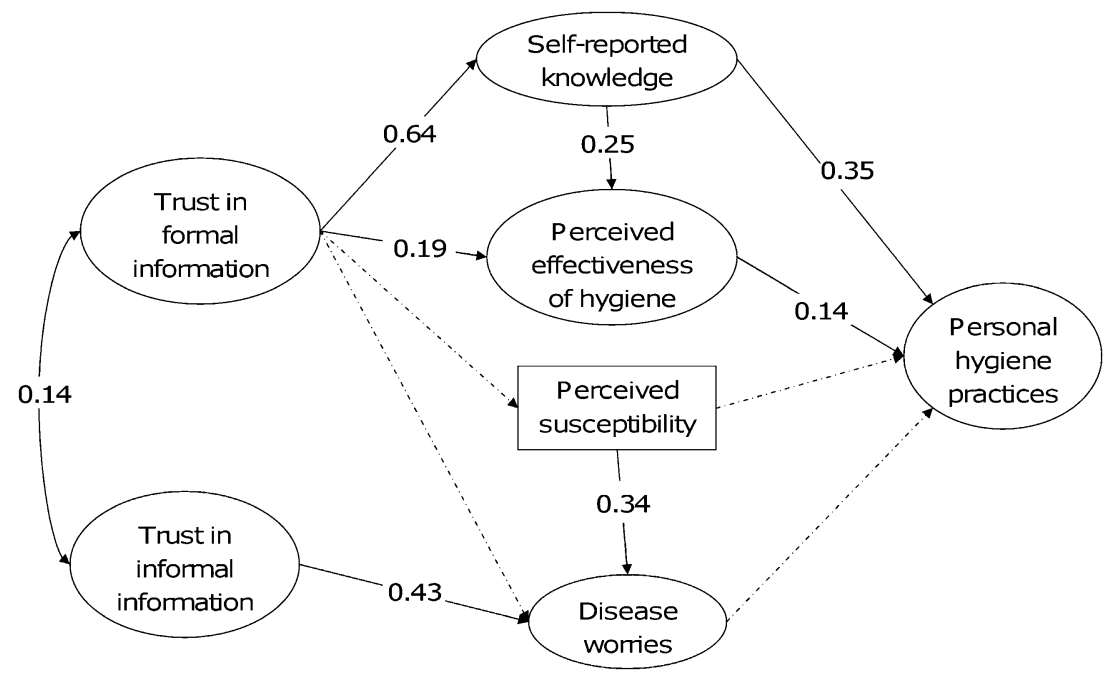

\section{$\mathrm{A} / \mathrm{H} 1 \mathrm{~N} 1$}

When applied to the $\mathrm{A} / \mathrm{H} 1 \mathrm{~N} 1$ dataset, the LMtest indicated the same paths (linking self-reported knowledge to perceived hygiene effectiveness and linking perceived susceptibility to disease worry) as in the H5N1 model be added to the model, while the Wtest indicated three paths including paths linking trust in informal information to self-reported knowledge, trust in informal information to perceived hygiene effectiveness, and trust in informal information to perceived susceptibility be removed. The final $\mathrm{A} / \mathrm{H} 1 \mathrm{~N} 1$ model structure was the same as that for the $\mathrm{A} / \mathrm{H} 5 \mathrm{~N} 1$ model but weights ( $\beta \mathrm{s})$ of corresponding paths differed notably (Fig. 3). The model fit indices indicated a good fit with $\mathrm{SB} \chi^{2} / d f=1.54, \mathrm{NNFI}=0.96, \mathrm{CFI}=0.97$ and $\mathrm{RMSEA}=0.02$.

Greater trust in formal information was strongly associated with better self-reported knowledge $(\beta=0.64)$ but, in contrast to the $\mathrm{A} / \mathrm{H} 5 \mathrm{~N} 1$ model, weakly (dashed $\beta<0.1$ ) associated with disease worry. Also, unlike the A/H5N1 model, disease worry weakly (dashed $\beta<0.1$ ) associated with PHPs, leaving only self-reported causal knowledge $(\beta=0.35)$ and perceived hygiene effectiveness $(\beta=0.14)$ associated with PHP. As in the A/H5N1 model trust in formal information was positively associated with perceived hygiene effectiveness ( $\beta=0.19)$, greater self-reported causal knowledge was associated with greater perceived hygiene effectiveness $(\beta=0.25)$ and greater perceived susceptibility was associated with more influenza worry $(\beta=0.34)$. Other paths were either weak (dashed, $\beta<0.1)$ or nonsignificant (absent). The model explained $17.7 \%$ of variance of PHP against A/H1N1.

Mediation analysis of these paths using the method of Barron and Kenny [54] found trust in formal information association with perceived prevention effectiveness was partially mediated by causal knowledge only for $\mathrm{A} / \mathrm{H} 1 \mathrm{~N} 1$ data (without knowledge mediation $\beta=0.42$; with mediation $\beta=0.35$, where a decline in the value of $\beta$ on inclusion of the putative mediating variable ("with mediation") indicates degree of mediation $(\sim 17 \%)$ ). Association between trust in formal information and PHPs was strongly mediated by perceive prevention effectiveness (without perceived prevention effectiveness mediation $\beta=0.13$; with mediation $\beta=0.05$ (n.s.), $\sim 61 \%$ mediation) for $\mathrm{A} / \mathrm{H} 5 \mathrm{~N} 1$, but far less so in the case of $\mathrm{A} / \mathrm{H} 1 \mathrm{~N} 1$ (without mediation $\beta=0.24$; with mediation $\beta=0.20, \sim 17 \%$ mediation). Perceived susceptibility mediation between trust in informal information and worry was absent in $\mathrm{A} / \mathrm{H} 5 \mathrm{~N} 1$ data and marginal (without mediation $\beta=0.46$; with mediation $\beta=0.41, \sim 11 \%$ mediation) in $\mathrm{A} / \mathrm{H} 1 \mathrm{~N} 1$ data.

\section{Discussion}

We tested hypotheses representing how trust in formal/ informal information might influence knowledge of influenza cause and perceived effectiveness of interventions, perceived susceptibility to and worry about influenza, and thereby personal hygiene. The null hypothesis of a fully saturated model was rejected in favour of a parsed final model partially approximating to that hypothesized. PHP variance was consistently explained by perceived PHP effectiveness, which in turn was associated with trust in formal information. However, counter intuitively, causal knowledge, while consistently associated with reported PHPs only associated with trust in formal information for A/H1N1 data. Counter to what was hypothesized, perceived susceptibility was unrelated to trust in information and reported PHP, being only associated with influenza worry, which itself contributed to PHP variance only for $\mathrm{A} / \mathrm{H} 5 \mathrm{~N} 1$ data. Trust in formal/informal information explained significant variance in influenza worry only for A/H5N1. Otherwise, the hypothesized model showed good fit to different data sets, from different times and influenza types. Variability in influenza characteristics probably contributed to differences 
in the model path weights. Despite A/H5N1, having a high case-fatality-rate [55], no deaths were attributed A/H5N1 in Hong Kong since 2002. Primarily a poultry disease, urban dwellers fear A/H5N1 [56, 57], liking it to SARS [56, 58, 59]. Rural dwellers, being familiar with zoonoses are less concerned [56, 57]. In contrast, $\mathrm{A} / \mathrm{H} 1 \mathrm{~N} 1$ is perceived as a mild non-threatening event in Hong Kong [40].

Demographic Differences These featured as determinants in many studies of PHP for RID prevention [11]. We found similar differences but remain unsure why such differences exist, or what they mean, examining these in more detail elsewhere [56, 57, 60]. We incorporated elements from TPB (perceived effectiveness) and from HBM (knowledge, perceived susceptibility), and incorporated negative affectivity (worry), which many theoretical models exclude. Trust in informal information was strongly correlated with age in both datasets, but level of disease worry was higher for $\mathrm{A} / \mathrm{H} 5 \mathrm{~N} 1$ than for $\mathrm{A} / \mathrm{H} 1 \mathrm{~N} 1$ while levels of perceived susceptibility were comparable for both influenzas and showed age trends probably reflecting differential influenza experience. In both cases, trust was marginally higher in $\mathrm{A} /$ $\mathrm{H} 1 \mathrm{~N} 1$ than $\mathrm{A} / \mathrm{H} 5 \mathrm{~N} 1$ data, probably reflecting historical factors. Following SARS trust in government was low and this took time to recover. Age-related differences were also found, with older people reporting more trust, consistent with other studies [11]. Given that perceived risk varies by demographic factors for crime [61], roads [62], cancer [63] and infection [26, 64], with more complex gender interactions seen on closer scrutiny [65] our findings are unsurprising.

Trust in Formal Information This consistently associated with both perceived PHP effectiveness, which consistent with other studies [10-15] associated strongly with PHPs. As hypothesized, perceptions of hygiene effectiveness were associated with greater personal hygiene practices, consistent with previous empirical studies [10-15, 24, 42, 66, 67], suggesting that adequate public understanding of RID cause and efficacy of prevention measures is paramount. While most studies on perceived PHP effectiveness report a link with practice, some studies have not found this [15]. Additionally, we found perceived PHP effectiveness strongly mediated trust in formal information associated with reported PHP in $\mathrm{A} / \mathrm{H} 5 \mathrm{~N} 1$ data, but only weakly mediated this association in $\mathrm{A} / \mathrm{H} 1 \mathrm{~N} 1$ data. This suggests differences in influenza characteristics and/or historical changes in perceptions of PHP effectiveness since A/H5N1. Established patterns of PHPs may have been unaffected by additional formal messages for PHP for A/H1N1. Various PHP elements may be differentially influenced by message characteristics [60]. Reported knowledge of influenza cause did not mediate perceived PHP effectiveness, suggesting that additional influences need to be incorporated in future studies.
Trust in Informal Information Greater trust in informal information was associated only with older age and greater worry. How others act or what they say provide important environmental cues to action [29]. Chinese culture considers social conformity to be important, so monitoring the behaviour and attitudes of others may provide important threat-related information to inform decision-making. Perhaps epidemic disease-related worry remains low until peoples' observations of others' statements and behaviours indicate action is warranted, arousing a motivating affect and hence behavioural response [33]. However, a strong disease worry link to better personal hygiene was seen only for $\mathrm{A} / \mathrm{H} 5 \mathrm{~N} 1$, consistent with previous studies [56, 57]. Possibly, behavioural change may occur only when disease worry exceeds a certain threshold [35-37]. This suggests that risk communications generating moderate worry might be most effective for prompting appropriate hygiene behaviour [68]. Informal social influences deserve closer scrutiny in RID research.

Limitation This study's limitations include being a secondary analysis of data collected for other purposes. Methodological heterogenity affected sampling and measurement. A greater proportion of women in the $\mathrm{A} / \mathrm{H} 5 \mathrm{~N} 1$ sample inflating known demographic differences in risk perception and PHPs may account for some of the reported associations in the A/H5N1 dataset. However, variable means of the two samples were not markedly dissimilar (Appendix Table 3). Being crosssectional, causal direction is ambiguous. Some variables measured with single items are sub-optimally defined, possibly raising validity and reliability concerns, the alpha values are low for some constructs and the variance accounted for is relatively modest for both models. Reporting of PHPs may have been inflated, subject to social desirability and retrospective recall biases. This needs to be borne in mind when interpreting the findings.

Public Health Implication Our findings reporting actual PHP behaviour, though cross-sectional, are consistent with the literature on risk communications, which strongly indicates that trustworthiness is a key variable in persuasion [68]. However, improvement in knowledge may be the most important consequence of trust in formal/informal information. During uncertainty, trust in formal information may modulate disease-related worry less than might the activities and beliefs expressed by trusted peers, family and perhaps even strangers. An example is face-mask use, which being highly visible takes on a semiotic function [8]. To generate a critical mass of appropriate behaviour in the community, prompt, clear and evidence-based public health information should help to maximize formal information trust [13].

News reports about H5N1 and H1N1 from the Hong Kong government website and two popular free newspapers during the respective survey periods emphasized new human A/ 
H5N1 cases in mainland China, (no local cases) during the A/ H5N1 survey. During the A/H1N1 survey, when A/H1N1 was still confined to North America, these sources addressed Hong Kong governmental containment responses to the outbreak. In contrast to the then somewhat familiar A/H5N1, A/H1N1 was an unknown, apparently aggressive human strain. Different media coverage, the hangover from SARS, and public health education on PHP since 2003 [69, 70] likely influenced trust in formal information and improved influenza knowledge. Perceived susceptibility was apparently insignificant in this process, contrary to earlier findings [11]. Difference between datasets suggests that real or perceived epidemic/pandemic characteristics might significantly modulate PHPs. The geographic proximity and imminence of epidemic threat should therefore be considered as an influence in future studies of RIDs. New preventive knowledge is more likely to be from formal than informal sources [71].

\section{Implications for Theory}

The associations between the cognitive factors and PHPs found in our study are largely consistent with previous RID studies [11], most of which lack a robust theoretical basis [11]. In extending core cognitive-affective components by incorporating the role of information trust, in particular social information our model more closely approximates an active RID epidemic/pandemic [33]. Differences between the two influenzas might reflect sample difference or indicate that influenza characteristics are themselves an important component driving situation awareness and response and should be factored into models to improve predictive power. Moreover, unlike most cognitive-behavioural models, our model accommodates cognitive and affective elements constituting mental representation of the threat posed by a RID epidemic/pandemic, consistent with the common sense model of illness [72]. Future studies should target theory development to reconcile divergent models and accommodate different findings. Overall, our study provides a stronger foundation from which to develop better behavioural models of responses to future RID epidemics.

Acknowledgments This paper comprised data from two projects. The A/H5N1 survey was part of the pan-Asian collaboration for behavioural surveillance on infectious disease risk funded by the Research Fund for the Control of Infectious Diseases Food and Health Bureau, Government of the Hong Kong SAR (grant no. 02040172), and the A/H1N1 survey received financial support from the Research Fund for the Control of Infectious Disease, Food and Health Bureau, Government of the Hong Kong SAR (grant no. PHE-01), the Harvard Center for Communicable Disease Dynamics from the US National Institutes of Health Models of Infectious Disease Agent Study programme (grant no. 1 U54 GM088558), and the Area of Excellence Scheme of the Hong Kong University Grants Committee (grant no. AoE/M-12/06).

We thank Ms. Ella Ho for coordinating the data collection and Ms Miyako Tsuchiya for data management and extensive database support in the A/H5N1 survey. For the A/H1N1 survey, we thank the HKU Public Opinion Programme for assistance in administering the telephone survey. We thank Dennis Ip, Angela Shen and Joseph Wu for helpful discussions, and Lincoln Lau, Diane Ng and Vicky Fang for technical assistance.

Open Access This article is distributed under the terms of the Creative Commons Attribution Noncommercial License which permits any noncommercial use, distribution, and reproduction in any medium, provided the original author(s) and source are credited.

\section{Appendix}

Table 1 Overview of study measures

\begin{tabular}{|c|c|c|c|c|}
\hline \multirow[t]{2}{*}{ Construct in the models } & \multicolumn{2}{|l|}{ Items } & \multirow[t]{2}{*}{ Response } & \multirow{2}{*}{$\begin{array}{l}\alpha \text { H5N1 } \\
(\alpha \text { H1N1) }\end{array}$} \\
\hline & Avian flu survey & Swine flu survey & & \\
\hline Trust in formal information & $\begin{array}{l}\text { Persuaded by what I read in } \\
\text { the paper about bird flu } \\
\text { Government health } \\
\text { spokesperson is trustworthy } \\
\text { Media report can be trusted } \\
\text { Trust what the government } \\
\text { say about bird flu } \\
\text { Trust the government do } \\
\text { what is needed to protect } \\
\text { our health }\end{array}$ & $\begin{array}{l}\text { Persuaded by what I read in the } \\
\text { paper about swine flu } \\
\text { Confident that government's } \\
\text { information is helpful } \\
\text { Media report can be trusted } \\
\text { Trust what the government say } \\
\text { about swine flu }\end{array}$ & 1-5 agreement & $0.72(0.66)$ \\
\hline Trust in informal information & $\begin{array}{l}\text { Best source of information about } \\
\text { bird flu is to watch and } \\
\text { listen to what others say } \\
\text { Tend to believe what my friends, } \\
\text { colleagues or neighbours } \\
\text { say about bird flu }\end{array}$ & $\begin{array}{l}\text { Best source of information about } \\
\text { swine flu is to watch and listen } \\
\text { to what others say } \\
\text { Tend to believe what my friends, } \\
\text { colleagues or neighbours say } \\
\text { about swine flu }\end{array}$ & 1-5 agreement & $0.29^{\mathrm{a}}(0.33)^{\mathrm{a}}$ \\
\hline
\end{tabular}


Table 1 (continued)

\begin{tabular}{|c|c|c|c|c|}
\hline \multirow[t]{2}{*}{ Construct in the models } & \multicolumn{2}{|l|}{ Items } & \multirow[t]{2}{*}{ Response } & \multirow{2}{*}{$\begin{array}{l}\alpha \mathrm{H} 5 \mathrm{~N} 1 \\
(\alpha \mathrm{H} 1 \mathrm{~N} 1)\end{array}$} \\
\hline & Avian flu survey & Swine flu survey & & \\
\hline Disease worry & $\begin{array}{l}\text { Friends have expressed } \\
\text { worries about bird flu } \\
\text { I am scared of catching bird flu }\end{array}$ & $\begin{array}{l}\text { Friends have expressed worries } \\
\text { about swine flu } \\
\text { I am worried about catching } \\
\text { swine flu }\end{array}$ & $1-5$ agreement & $0.45(0.59)$ \\
\hline & $\begin{array}{l}\text { Things read in the newspaper } \\
\text { about bird flu scared me }\end{array}$ & $\begin{array}{l}\text { Things read in the newspaper } \\
\text { about swine flu scared me }\end{array}$ & & \\
\hline Perceived susceptibility & $\begin{array}{l}\text { Likelihood of contracting } \\
\text { avian flu }\end{array}$ & Likelihood of contacting swine flu & 1-7 likelihood & \\
\hline Self-reported knowledge & $\begin{array}{l}\text { I understand how bird flu caused } \\
\text { I know how to prevent myself } \\
\text { and family against bird flu }\end{array}$ & $\begin{array}{l}\text { I understand how people get } \\
\text { infected with swine flu } \\
\text { I know how to prevent myself } \\
\text { and family against swine flu }\end{array}$ & $1-5$ agreement & $0.32^{\mathrm{a}}(0.27)^{\mathrm{a}}$ \\
\hline $\begin{array}{l}\text { Perceived hygiene effectiveness } \\
\text { in prevention }\end{array}$ & $\begin{array}{l}\text { Washing hands before touching } \\
\text { face or food } \\
\text { Washing hands after going out }\end{array}$ & $\begin{array}{l}\text { Washing hands before eating } \\
\text { Washing hands after coming back }\end{array}$ & $\begin{array}{l}1-5 \\
\text { effectiveness }\end{array}$ & $0.76^{\mathrm{a}}(0.51)^{\mathrm{a}}$ \\
\hline $\begin{array}{l}\text { Personal hygiene practices in the past } \\
3 \text { days }\end{array}$ & $\begin{array}{l}\text { Cover mouth when sneezing } \\
\text { or coughing } \\
\text { Wash hands after sneezing, } \\
\text { coughing or touching nose } \\
\text { Use liquid soap when washing } \\
\text { hands } \\
\text { Use serving utensils when } \\
\text { dining with others }\end{array}$ & $\begin{array}{l}\text { Cover mouth when sneezing or } \\
\text { coughing } \\
\text { Wash hands after sneezing, } \\
\text { coughing or touching nose } \\
\text { Use serving utensils when } \\
\text { dining with others }\end{array}$ & $1-4$ frequency & $0.56(0.42)$ \\
\hline
\end{tabular}

${ }^{a}$ Pearson's correlation due to only two items

Table 2 Comparison between samples' and general population's demographic structures, Hong Kong

\begin{tabular}{|c|c|c|c|c|c|}
\hline Demographics & A/H5N1 (survey $n=1,760)$ & A/H1N1 survey $(n=1,016)$ & $\chi^{2}(p)^{\mathrm{a}}$ & Population structure $^{\mathrm{b}}$ & Effect size $^{c}$ \\
\hline \multicolumn{6}{|l|}{ Gender } \\
\hline Female & $64 \%$ & $54 \%$ & \multirow[t]{2}{*}{$3.90(0.048)$} & $52.3 \%$ & \multirow[t]{2}{*}{$0.23(0.03)$} \\
\hline Male & $36 \%$ & $46 \%$ & & $47.7 \%$ & \\
\hline \multicolumn{6}{|l|}{ Age group } \\
\hline $18-34$ & $25 \%$ & $29 \%$ & \multirow[t]{3}{*}{$39.74(<0.001)$} & $33.1 \%$ & \multirow[t]{3}{*}{$0.26(0.10)$} \\
\hline $35-54$ & $54 \%$ & $42 \%$ & & $41.2 \%$ & \\
\hline$\geq 55$ & $21 \%$ & $29 \%$ & & $25.7 \%$ & \\
\hline \multicolumn{6}{|l|}{ Education } \\
\hline Primary or below & $19 \%$ & $16 \%$ & \multirow[t]{3}{*}{$10.21(0.006)$} & $25.4 \%$ & \multirow[t]{3}{*}{$0.15(0.24)$} \\
\hline Secondary & $56 \%$ & $53 \%$ & & $51.6 \%$ & \\
\hline Tertiary or above & $25 \%$ & $30 \%$ & & $23 \%$ & \\
\hline \multicolumn{6}{|l|}{ Marital status } \\
\hline Single & $28 \%$ & $33 \%$ & \multirow[t]{2}{*}{$7.57(0.006)$} & $32.4 \%$ & \multirow[t]{2}{*}{$0.09(0.01)$} \\
\hline Married or formerly married & $72 \%$ & $67 \%$ & & $67.6 \%$ & \\
\hline \multicolumn{6}{|l|}{ Birth place } \\
\hline Hong Kong & $66 \%$ & $69 \%$ & \multirow[t]{2}{*}{$2.58(0.108)$} & $60.3 \%$ & \multirow[t]{2}{*}{$0.12(0.18)$} \\
\hline Other places & $34 \%$ & $31 \%$ & & $39.7 \%$ & \\
\hline
\end{tabular}

${ }^{a}$ The demographic differences between the H5N1 and H1N1 surveys

${ }^{\mathrm{b}}$ Based on 2006 Hong Kong by-census (Census and Statistics Department HKSAR)

${ }^{\mathrm{c}}$ Effect sizes $w$ are calculated via the formula $w=\sqrt{\sum_{i=1}^{m} \frac{\left(p_{0}(i)-p_{1}(i)\right)^{2}}{p_{0}(i)}}$, where $P_{0}(i)$ and $P_{1}(i)$ are the observed proportions in the $i$ th category from the
by-census data and survey data, respectively Values reported outside the brackets refer to effect size of A/H5N1 sample while values reported inside the brackets refer to effect size of A/H1N1 sample 
Table 3 Gender and age differences of the constructs

\begin{tabular}{|c|c|c|c|c|c|c|}
\hline \multirow[t]{2}{*}{ Variables } & \multicolumn{2}{|c|}{ H5N1 survey } & \multicolumn{2}{|c|}{ H1N1 survey } & \multirow{2}{*}{$\begin{array}{l}\text { Gender } \\
\text { differences }(t)^{\mathrm{e}}\end{array}$} & \multirow{2}{*}{$\begin{array}{l}\text { Correlation with ag } \\
\text { H5N1 (H1N1) }\end{array}$} \\
\hline & $\begin{array}{l}\text { Female } \\
\text { (SD) }\end{array}$ & Male (SD) & $\begin{array}{l}\text { Female } \\
\text { (SD) }\end{array}$ & Male (SD) & & \\
\hline Hygiene practices ${ }^{c}$ & $3.10(0.58)$ & $2.90(0.61)$ & $3.09(0.72)$ & $2.86(0.76)$ & $6.90^{\mathrm{b}}\left(4.22^{\mathrm{b}}\right)$ & $-0.01\left(0.09^{\mathrm{a}}\right)$ \\
\hline Self-reported knowledge ${ }^{\mathrm{c}}$ & $3.54(0.57)$ & $3.58(0.57)$ & $3.60(0.66)$ & $3.64(0.76)$ & $-1.61(-0.81)$ & $-0.04(0.06)$ \\
\hline Perceived effectiveness ${ }^{\mathrm{c}}$ & $3.53(0.59)$ & $3.45(0.59)$ & $3.57(0.49)$ & $3.54(0.54)$ & $2.74^{\mathrm{b}}(0.84)$ & $0.07^{\mathrm{b}}\left(0.13^{\mathrm{b}}\right)$ \\
\hline Perceived susceptibility & $3.25(1.33)$ & $3.14(1.33)$ & $3.23(1.17)$ & $3.12(1.16)$ & $1.59(1.25)$ & $-0.15^{\mathrm{b}}\left(0.11^{\mathrm{b}}\right)$ \\
\hline Disease worry $^{\mathrm{c}}$ & $2.89(0.61)$ & $2.80(0.62)$ & $2.67(0.79)$ & $2.57(0.80)$ & $2.96^{\mathrm{b}}(1.70)$ & $0.08^{\mathrm{b}}\left(0.08^{\mathrm{a}}\right)$ \\
\hline Trust in formal information ${ }^{c}$ & $3.62(0.44)$ & $3.57(0.48)$ & $3.89(0.53)$ & $3.87(0.57)$ & $2.20^{\mathrm{a}}(0.57)$ & $0.13^{\mathrm{b}}(0.03)$ \\
\hline Trust in informal information ${ }^{\mathrm{c}}$ & $2.32(0.52)$ & $2.33(0.58)$ & $2.49(0.82)$ & $2.46(0.85)$ & $-0.27(0.39)$ & $0.26^{\mathrm{b}}\left(0.26^{\mathrm{b}}\right)$ \\
\hline
\end{tabular}

${ }^{a}<0.05$

$\mathrm{b}_{<0.01}$

${ }^{\mathrm{c}}$ Mean construct score

${ }^{\mathrm{d}}$ Pearson's correlation with age, which is a continuous variable

${ }^{\mathrm{e}} \mathrm{T}-\mathrm{t}$ test to compare the differences between males and females for H5N1data and H1N1 data (within parentheses), respectively

\section{References}

1. World Health Organization Writing Group. Nonpharmaceutical interventions for pandemic influenza, national and community measures. Emerg Infect Dis. 2006;12:88-94.

2. Mounts AW, Kwong H, Izurieta HS, Ho Y, Au T, Lee M, et al. Case-control study of risk factors for avian influenza A (H5N1) disease, Hong Kong, 1997. J Infect Dis. 1999;180:505-8.

3. Zhou L, Liao Q, Dong L, Huai Y, Bai T, Xiang N, et al. Risk factors for human illness with avian influenza A (H5N1) virus infection in China. J Infect Dis. 2009;199:1726-34.

4. Peiris JS, Poon LL, Guan Y. Emergence of a novel swine-origin influenza a virus (S-OIV) H1N1 virus in humans. J Clin Virol. 2009;45:169-73.

5. Grayson ML, Melvani S, Druce J, Barr IG, Ballard SA, Johnson $\mathrm{PD}$, et al. Efficacy of soap and water and alcohol-based hand-rub preparations against live H1N1 influenza virus on the hands of human volunteers. Clin Infect Dis. 2009;48:285-91.

6. Jefferson T, Del Mar C, Dooley L, Ferroni E, Al-Ansary LA, Bawazeer GA, et al. Physical interventions to interrupt or reduce the spread of respiratory viruses: systematic review. BMJ. 2009;339:b3675.

7. Cowling BJ, Chan KH, Fang VJ, Cheng CK, Fung RO, Wai W, et al. Facemasks and hand hygiene to prevent influenza transmission in households: a cluster randomized trial. Ann Intern Med. 2009;151:437-46.

8. Syed Q, Sopwith W, Regan M, Bellis MA. Behind the mask. Journey through an epidemic: some observations of contrasting public health responses to SARS. J Epidemiol Community Health. 2003;57:855-6.

9. Wong TW, Tam WS. Handwashing practice and the use of personal protective equipment among medical students after the SARS epidemic in Hong Kong. Am J Infect Control. 2005;33:580-6.

10. Leppin A, Aro AR. Risk perceptions related to SARS and avian influenza: theoretical foundations of current empirical research. Int J Behav Med. 2009;16:7-29.

11. Bish A, Michie S. Demographic and attitudinal determinants of protective behaviours during a pandemic: a review. Br J Health Psychol. 2010. doi:10.1348/135910710X485826.

12. Slovic P. Trust, emotion, sex, politics, and science: surveying the risk-assessment battlefield. Risk Anal. 1999;19:689-701.
13. Vaughan E, Tinker T. Effective health risk communication about pandemic influenza for vulnerable populations. Am J Public Health. 2009;99 Suppl 2:S324-32.

14. Rubin GJ, Amlot R, Page L, Wessely S. Public perceptions, anxiety, and behaviour change in relation to the swine flu outbreak: cross sectional telephone survey. BMJ. 2009;339:b2651.

15. Tang CS, Wong CY. Psychosocial factors influencing the practice of preventive behaviors against the severe acute respiratory syndrome among older Chinese in Hong Kong. J Aging Health. 2005; 17:490-506.

16. Ajzen I. Attitudes, personality and behavior. Chicago: Dorsey; 1988.

17. Ajzen I. The theory of planned behaivor. Organ Behav Hum Decis Process. 1991;50:179-211.

18. Fishbein M, Ajzen I. Attitudes towards objects as predictors of single multiple behavioral criteria. Psychol Rev. 1974;81:59-74.

19. Ajzen I, Fishbein M. Understanding attitudes, and predicting social behavior. Englewood Cliffs: Prentice Hall; 1980.

20. Becker MH. The health belief model and personal health behaviour. Thorofare: Slack; 1974.

21. Becker MH, Haefner DP, Maiman LA. The health belief model in the prediction of dietary compliance: a field experiment. J Health Soc Behav. 1977;18:348-66.

22. Rogers RW. A protection motivation theory of fear appeals and attitude change. J Psychol. 1975;91:93-114.

23. Quinn SC, Kumar S, Freimuth VS, Kidwell K, Musa D. Public willingness to take a vaccine or drug under emergency use authorization during the $2009 \mathrm{H} 1 \mathrm{~N} 1$ pandemic. Biosecur Bioterror. 2009; 7:275-90.

24. Tang CS, Wong CY. An outbreak of the severe acute respiratory syndrome: predictors of health behaviors and effect of community prevention measures in Hong Kong, China. Am J Public Health. 2003;93:1887-8.

25. Bandura A. Social learning theory. New Jersey: Prentice Hall; 1977.

26. De Wandel D, Maes L, Labeau S, Vereecken C, Blot S. Behavioral determinants of hand hygiene compliance in intensive care units. Am J Crit Care. 2010;19:230-9.

27. Calman KC. Communication of risk: choice, consent, and trust. Lancet. 2002;360:166-8.

28. Rosen NO, Knauper B. A little uncertainty goes a long way: state and trait differences in uncertainty interact to increase information seeking but also increase worry. Health Commun. 2009;24:22838. 
29. Bandura A. Social foundations of thought and action: a social cognitive theory. Englewood Cliffs: Prentice Hall; 1986.

30. Voeten HA, de Zwart O, Veldhuijzen IK, Yuen C, Jiang X, Elam G, et al. Sources of information and health beliefs related to SARS and avian influenza among Chinese communities in the United Kingdom and The Netherlands, compared to the general population in these countries. Int $\mathrm{J}$ Behav Med. 2009; 16:49-57.

31. Leventhal H, Safer MA, Paganis D. The impact of communications on health beliefs, decisions, and behaviours. Health Educ Q. 1983;10:1-29.

32. Petty R, Cacioppo J. In: Berkowitz L, editor. The elaboration likelihood model of persuasion. Orlando: Academic; 1986.

33. Slaughter L, Keselman A, Kushniruk A, Patel VL. A framework for capturing the interactions between laypersons' understanding of disease, information gathering behaviors, and actions taken during an epidemic. J Biomed Inform. 2005;2005:298-313.

34. Lazarus RS, Folkman S. Stress, appraisal, and coping. New York: Springer; 1984.

35. Smith CA, Lazarus RS. Appraisal components, core relational themes, and the emotions. Cogn Emot. 1993;7:233-69.

36. Spector PE, Zapf D, Chen PY, Frese M. Why negative affectivity should not be controlled in job stress research: don't throw the baby out with the bath water. J Organ Behav. 2000;21:79-95.

37. Oliver J, Brough P. Cognitive appraisal, negative affectivity and psychological well-being. 2002. Available from: http://findarticles.com/p/articles/mi_qa3848/is_200206/ai_n9102415/?tag=content;coll. Accessed 14 September 2010.

38. Endsley MR. Toward a theory of situation awareness in dynamic systems. Hum Factors. 1997;37:32-64.

39. Fielding R, Bich TH, Quang LN, Lam WW, Leung GM, Tien TQ, et al. Live poultry exposures, Hong Kong and Hanoi, 2006. Emerg Infect Dis. 2007;13:1065-7.

40. Cowling BJ, Ng MW, Ip KM, Liao Q, Lam WT, Wu JT, et al. Community psychological and behavioral responses through the first wave of 2009 pandemic (H1N1) in Hong Kong. J Infect Dis. 2010;202:867-76.

41. Perez-Padilla R, de la Rosa-Zamboni D, Ponce de Leon S, Hernandez M, Quinones-Falconi F, Bautista E, et al. Pneumonia and respiratory failure from swine-origin influenza A (H1N1) in Mexico. N Engl J Med. 2009;361:680-9.

42. Wong CY, Tang CS. Practice of habitual and volitional health behaviors to prevent severe acute respiratory syndrome among Chinese adolescents in Hong Kong. J Adolesc Health. 2005;36:193-200.

43. Cohen J. Statistical power analysis for the behavioral sciences. 2nd ed. Hillsdale: Erlbaum; 1988.

44. Byrne BM. Structural equation modeling with EQS: basic concepts, applications, and programming. 2nd ed. New Jersey: Lawrence Erlbaum Associates, Inc.; 2006.

45. King G, Honaker J, Joseph A, Scheve K. Analyzing incomplete political science data: an alternative algorithm for multiple imputation. Am Polit Sci Rev. 2001;95:49-69.

46. Little RJA, Rubin DB. Statistical analysis with missing data. Hoboken: Wiley; 2002.

47. Kline RB. Principles and practice of structural equation modeling. New York: Guiford; 1998.

48. Satorra A. Scaled and adjusted restricted tests in multi-sample analysis of moment structures, economics working papers 3951999. Available from: http://ideas.repec.org/s/upf/upfgen.html. Accessed 5 July 2010.

49. Munro BH. Statistical methods for health care research. 5th ed. Philadelphia: Lippincott Williams \& Wilkins; 2005.

50. Bentler PM, Wu EJC. EQS 6 for Windows user's guide. Encino, CA: Multivariate Software, Inc.; 2002.
51. Hong Kong Census and Statistics Department. Main tables of the 2006 population census. Hong Kong: Government of the Hong Kong SAR. 2006. Available from: http://www.bycensus2006.gov. hk/en/data/data3/statistical_tables/index.htm\#A1. Accessed 10 June 2010.

52. Chapman GB, Coups EJ. Emotions and preventive health behavior: worry, regret, and influenza vaccination. Health Psychol. 2006;25:82-90.

53. Weinstein ND, Kwitel A, McCaul KD, Magnan RE, Gerrard M, Gibbons FX. Risk perceptions: assessment and relationship to influenza vaccination. Health Psychol. 2007;26:14651.

54. Baron RM, Kenny DA. The moderator-mediator variable distinction in social psychological research: conceptual, strategic, and statistical considerations. J Pers Soc Psychol. 1986;51:1173-82.

55. World Health Organization. Cumulative Number of Confirmed Human Cases of Avian Influenza A/(H5N1) Reported to WHO. 2010 [updated 6th May, 2010]. Available from: http://www.who. int/csr/disease/avian_influenza/country/cases_table_2010_05_06/ en/index.html. Accessed 11 May 2010.

56. Liao Q, Lam WW, Jiang CQ, Ho EY, Liu YM, Zhang WS, et al. Avian influenza risk perception and live poultry purchase in Guangzhou, China, 2006. Risk Anal. 2009;29:416-24.

57. Liao QY, Lam WWT, Dang VT, Jiang CQ, Udomprasertgul V, Fielding R. What causes $\mathrm{H} 5 \mathrm{~N} 1$ avian influenza? Lay perceptions of H5N1 etiology in South East and East Asia. J Pub Health. 2009;31:573-81.

58. Lau JT, Kim JH, Tsui HY, Griffiths S. Anticipated and current preventive behaviours in response to an anticipated human-tohuman $\mathrm{H} 5 \mathrm{~N} 1$ epidemic in the Hong Kong Chinese general population. BMC Infect Dis. 2007;7:18-29.

59. Hong S, Collins A. Societal responses to familiar versus unfamiliar risk: comparisons of influenza and SARS in Korea. Risk Anal. 2006;26:1247-57.

60. Liao Q, Cowling BJ, Lam WT, Ng DMW, Fielding R. Situational awareness and health protective responses to pandemic influenza A (H1N1) in Hong Kong: a cross-sectional study. PLoS ONE 2010. http://one.plosjms.org/pone files/2010/09/08/00113059/04/ 113059_4_art_1_199kbn.pdf

61. Lagrange RL, Ferraro KF. Assessing age and gender differences in perceived risk and fear of crime. Criminol. 2006;27:697-720.

62. Elvik R, Bjornskau T. How accurately does the public perceive differences in transport risks?: an exploratory analysis of scales representing perceived risk. Accident Anal Prev. 2005;37:2005-11.

63. Robb KA, Miles A, Wardle J. Demographic and psychosocial factors associated with perceived risk for colorectal cancer. Cancer Epidemiol Biomark Prev. 2004;13:366-72.

64. Murray R, Chandler C, Clarkson Y, Wilson N, Baker M, Cunningham R. Sub-optimal hand sanitiser usage in a hospital entrance during an influenza pandemic, New Zealand, August 2009. Euro Surveill. 2009;14(pii):19331.

65. Finucane NL, Slovic P, Mertz CK, Flynn KJ, Satterfield GA. Gender, race, and perceived risk: the 'white male' effect. Health Risk Soc. 2000;2:159-72.

66. Fatiregun AA, Saani MM. Knowledge, attitudes and compliance of poultry workers with preventive measures for avian influenza in Lagelu, Oyo State, Nigeria. J Infect Dev Ctries. 2008;2:130-4.

67. Leung GM, Ho LM, Chan SK, Ho SY, Bacon-Shone J, Choy RY, et al. Longitudinal assessment of community psychobehavioral responses during and after the 2003 outbreak of severe acute respiratory syndrome in Hong Kong. Clin Infect Dis. 2005;40:1713-20. 
68. Abraham T. Risk and outbreak communication: lessons from alternative paradigms. Bull World Health Organ. 2009;87:604-7.

69. Center for Health Protection Hong Kong. Prevention of avian influenza. 2005 [updated July 17, 2009]. Available from: http:// www.info.gov.hk/info/flu/eng/faq.htm. Accessed 28 August 2010.

70. Center for Health Protection Hong Kong. Human swine influenza. 2009 [updated November 8, 2009]. Available from: http://www. chp.gov.hk/view_content.asp?lang=en\&info_id=16615. Accessed 28 August 2010.

71. Berry TR, Wharf-Higgins J, Naylor PJ. SARS wars: an examination of the quantity and construction of health information in the news media. Health Commun. 2007;21:35-44.

72. Leventhal H, Meyer D, Nerenz D. The Common sense model of illness danger. New York: Pergamon; 1980. 